NOTE

\title{
Comparison of toxic effects of nitric oxide and peroxynitrite on Uronema marinum (Ciliata: Scuticociliatida)
}

\author{
Eun Hye Lee ${ }^{1}$, Sung Mi Kim", Se Ryun Kwon', Sung Koo Kim², Yoon Kwon Nam³, \\ Ki Hong Kim ${ }^{1, *}$
}

${ }^{1}$ Department of Aquatic Life Medicine, ${ }^{2}$ Faculty of Food Science and Biotechnology, and ${ }^{3}$ Department of Aquaculture, Pukyong National University, Pusan 608-737, Korea

\begin{abstract}
To discover the effects of nitric oxide (NO) and peroxynitrite on Uronema marinum (a ciliate responsible for systemic scuticociliatosis in cultured olive flounder Paralichthys olivaceus), the dose-dependent inhibitory effect of NO donors, $S$-nitroso- $N$-acetylpenicillamine (SNAP) and 3-morpholinosydnonimine (SIN-1) on the proliferation and survival of $U$. marinum was investigated. The inhibitory effects of exogenous superoxide dismutase (SOD) and catalase on the toxicity of SIN1 were also investigated. After $24 \mathrm{~h}$ of incubation in the presence of $0.2 \mathrm{mM} \mathrm{SNAP}$, the number of ciliates was not statistically different from that of the controls, whereas incubation in the presence of $0.5 \mathrm{mM}$ SNAP reduced the number of parasites significantly to $59.1 \%$ of controls. Concentrations of SNAP higher than $0.5 \mathrm{mM}$ resulted in greater reductions in the number of ciliates, but levels of generated NO far exceeded physiological ranges. The number of viable ciliates incubated for $24 \mathrm{~h}$ with $0.2 \mathrm{mM}$ SIN-1 was reduced significantly to $25.0 \%$, and all ciliates were killed by incubation in concentrations above $0.5 \mathrm{mM}$ SIN-1. Although SOD decreased the toxic effect of SIN-1 on $U$. marinum, protection was not complete and did not improve after increasing the SOD concentration from 50 to $400 \mathrm{U} \mathrm{ml}^{-1}$. Addition of catalase ranging from 500 to $10000 \mathrm{U} \mathrm{ml}^{-1}$ completely protected $U$. marinum from SIN-1 toxicity. Ciliates exposed to catalase alone or catalase plus SIN-1 showed significantly higher and dose-dependent proliferation rates compared to controls. Addition of haemoglobin, ranging from 0.5 to $2.0 \mathrm{mg} \mathrm{ml}^{-1}$, also protected $U$. marinum from SIN-1 toxicity, and increased the proliferation rate dose-dependently. In conclusion, resistance of $U$. marinum to oxidative and nitrative stress may allow this pathogen to withstand the NO- and oxygen-radical-dependent killing mechanisms of phagocytic cells.
\end{abstract}

KEY WORDS: Uronema marinum $\cdot$ Scuticociliatosis $\cdot$ Nitric oxide $\cdot$ Peroxynitrite $\cdot$ Cytotoxicity

\section{INTRODUCTION}

Several scuticociliate species belonging to the genera Uronema, Miamiensis and Philasterides, previously regarded as free-living environmental scavengers, are being recognized as serious opportunistic pathogens in marine fish (Thompson \& Moewus 1964, Cheung et al. 1980, Yoshinaga \& Nakazoe 1993, Dyková \& Figueras
1994, Dragesco et al. 1995, Gill \& Callinan 1997, Munday et al. 1997, Sterud et al. 2000, Iglesias et al. 2001). These ciliates are histophagous and characterized by their potential for systemic invasion and destroying fish tissues, leading to significant mortalities in cultured fish. In Korea, scuticociliatosis is a serious problem in cultured olive flounder Paralichthys olivaceus, and the causative agent has been identified, looking at 
morphological characteristics, as Uronema marinum (Jee et al. 2001). Systemic infection by scuticociliates in fish induced inflammatory cellular infiltration, consisting of macrophages, lymphocytes and granulocytes at the site of infection (Munday et al. 1997, Sterud et al. 2000, Iglesias et al. 2001) or no inflammatory responses (Cheung et al. 1980). Survival and establishment of systemic infections of scuticociliates suggests that they have a high degree of sustained resistance to, or subversion of, host immunity.

In mammals, there is abundant evidence that microbial and parasitic pathogens stimulate nitric oxide (NO) synthesis by inducible nitric oxide synthase (iNOS) in macrophages, and this constitutes an important arm of host defense (Clark \& Rockett 1996, Nathan \& Shiloh 2000). Recently, it has been demonstrated that fish leucocytes can also produce NO by activation of iNOS. iNOS activity has been detected in channel catfish leucocytes following experimental challenge with Edwardsiella ictaluri (Schoor \& Plumb 1994), and a goldfish macrophage cell line incubated with lipopolysaccharide (LPS) or supernatants from stimulated leucocytes has been shown to produce NO (Neumann et al. 1995). Campos-Perez et al. (2000) reported iNOS gene expression from various tissues of rainbow trout after challenge with Renibacterium salmoninarum. In carp, an iNOS cDNA was cloned, and its expression was studied in response to LPS and Trypanoplasma borreli challenges (Saeij et al. 2000). Saeij et al. (2002) reported that infection of $T$. borreli in carp activated NO production from phagocytes, but Trypanosoma carassii did not induce NO production in vivo, and inhibited LPS-induced NO production in vitro.

Along with NO generation, activated macrophages also produce superoxide. The reaction of NO with superoxide is extremely rapid (Huie \& Padmaja 1993) and results in the generation of peroxynitrite, which is a potent chemical oxidant in its protonated form (Koppenol et al. 1992, Nathan 1992, Bogdan et al. 2000). In mammals, coactivation of the respiratory burst and NO synthesis in macrophages or granulocytes could result in peroxynitrite formation (Ischiropoulos et al. 1992, Carreras et al. 1994). Since fish phagocytes have functional similarities to mammalian phagocytes, they are assumed to produce peroxynitrite, although this remains to be proven.

Studies on mammalian parasites have demonstrated that parasites have different susceptibility to NO or peroxynitrite. Intracellular parasites such as Leishmania (Liew et al. 1990) and extracellular parasites such as Entamoeba histolytica (Jarillo-Luna et al. 2002) or Giardia lamblia (Eckmann et al. 2000) can be killed or controlled by NO. However, Trypanosoma cruzi (Denicola et al. 1993) and Brugia malayi (Thomas et al. 1997) have been shown to be more susceptible to peroxynitrite than NO.

The effects of NO and peroxynitrite against scuticociliates have apparently not yet been investigated. Several proposed mechanisms concerning the cytotoxic action of NO have been advanced based on the use of various NO donor compounds. Among them, 3-morpholinosydnonimine (SIN-1) releases both NO and superoxide radicals in aqueous solutions, resulting in the formation of peroxynitrite, whereas $S$-nitroso- $N$ acetylpenicillamine (SNAP) releases only NO (Feelisch 1991, Hogg et al. 1992, Holm et al. 1998). Therefore, in the present study, the dose-dependent inhibitory effect of NO donors, SNAP and SIN-1 on the proliferation and survival of Uronema marinum was investigated. The inhibitory effects of exogenous superoxide dismutase (SOD) and catalase (CAT) on the toxic effects of SIN-1 were also investigated.

\section{MATERIALS AND METHODS}

Isolation and culture of Uronema marinum. U. marinum were isolated asceptically from the brain of infected olive flounders Paralichthys olivaceus inoculated into minimum essential medium (MEM, Sigma Chemical) containing $10 \%$ foetal calf serum (Sigma) and then incubated at $20^{\circ} \mathrm{C}$. The ciliates from logarithmic phase of growth were subcultured by inoculating ca. $1 \times 10^{5}$ cells into $200 \mathrm{ml}$ of the medium.

Effect of NO donors on the Uronema marinum viability and proliferation. Mid-log-phase cultures of the ciliates grown in the culture medium were washed and adjusted to a density of approximately $1 \times 10^{4}$ cells ml $^{-1}$ of MEM. The ciliates were inoculated into wells of flat-bottomed 96-well microplates at a density of $1 \times$ $10^{2}$ cells per well. The cytotoxic effect of SNAP (Sigma) and SIN-1 (Sigma) was determined by incubating the same number of ciliates for $24 \mathrm{~h}$ in the presence of a range of concentrations $(0.2,0.5,1.0,2.0$ and $5.0 \mathrm{mM}$ final concentration) of SNAP, SIN-1 or $N$-acetylpenicillamine (NAP, Sigma). Viable ciliates in each well of the plates were counted using a haemocytometer. All assays were performed in triplicate and cytotoxicity was expressed as the percentage of total number of ciliates in a treated well, divided by the number of ciliates in the control (MEM alone) well at $24 \mathrm{~h}$ post incubation.

Measurement of nitrite. Determination of the stable oxidation product nitrite (measured with Greiss reagent: $1 \%$ aminobenzenesulfonamide, $0.1 \%$ naphthylethylene diamine dihydrochloride in $2.5 \%$ phosphoric acid; Sigma) was used as an indicator of nitric oxide production. A triplicate aliquot of culture medium (MEM) containing $0,0.2,0.5,1.0,2.0$ or $5.0 \mathrm{mM}$ of each 
NO donor was incubated, while shaking, with an equal volume of Greiss reagent for $10 \mathrm{~min}$ at room temperature, and the absorbance was determined at $540 \mathrm{~nm}$. Nitrite concentrations were determined via a standard curve established with 1 to $200 \mu \mathrm{M}$ sodium nitrite prepared in MEM reacted with Greiss reagent under the same conditions.

Effect of SOD, CAT and haemoglobin on SIN-1 toxicity. The ciliates were exposed to $\operatorname{SOD}(50,100$, 200 and $400 \mathrm{U} \mathrm{ml}^{-1}$ final concentration; Sigma), CAT (500, 1000, 5000 and $10000 \mathrm{U} \mathrm{ml}^{-1}$ final concentration; Sigma), SOD+CAT $(25+250,50+500,100+2500$ and $200+5000 \mathrm{U} \mathrm{ml}^{-1}$ final concentration), and haemoglobin (0.01 to $2.0 \mathrm{mg} \mathrm{ml}^{-1}$ final concentration; Sigma) in the presence or absence of $1 \mathrm{mM}$ SIN-1, for $24 \mathrm{~h}$. The number of ciliates was determined as described above.

Statistical analysis. Data were compared and analyzed by Student's $t$-test, and p-values less than 0.01 were considered significant.

\section{RESULTS}

\section{Cytotoxic effect of SNAP and SIN-1 on Uronema marinum}

Incubation of 0.2 and $0.5 \mathrm{mM}$ SNAP for $24 \mathrm{~h}$ in the culture medium generated $120.92 \pm 0.37$ and $208.58 \pm$ $1.19 \mu \mathrm{M}$ (mean $\pm \mathrm{SD}$ ) nitrite, respectively. After $24 \mathrm{~h}$ of incubation in the presence of $0.2 \mathrm{mM} \mathrm{SNAP,}$ the number of ciliates was not statistically different from that of controls, whereas incubation in the presence of $0.5 \mathrm{mM}$ SNAP reduced the parasite number significantly ( $p<0.01$ ) to $59.1 \%$ that of controls (Fig. 1). Con-

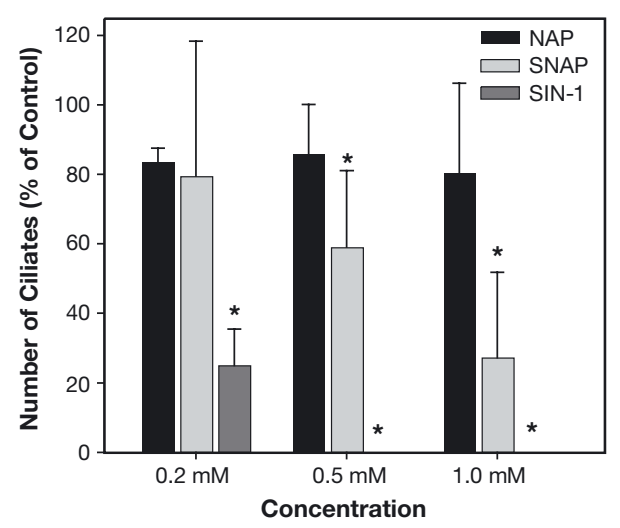

Fig. 1. Uronema marinum. Percentage of individuals exposed to various concentrations of $N$-acetylpenicillamine (NAP), $S$-nitroso- $N$-acetylpenicillamine (SNAP) and 3-morpholinosydnonimine (SIN-1) in minimum essential medium (MEM) for $24 \mathrm{~h}$. Ciliates were counted by a haemocytometer, and data are expressed as means $\pm \mathrm{SD}$ of triplicate assays. $\star p<0.01$, versus ciliates cultured in MEM alone (control) centrations of SNAP higher than $0.5 \mathrm{mM}$ resulted in greater reductions in the number of ciliates, but the levels of NO generated far exceeded physiological ranges. The control compound NAP (0.2 to $5.0 \mathrm{mM})$ did not generate detectable levels of nitrite, and did not significantly influence the number of viable ciliates.

Incubation of 0.2 and $0.5 \mathrm{mM} \mathrm{SIN-1}$ for $24 \mathrm{~h}$ in the culture medium generated $66.77 \pm 1.00$ and $150.78 \pm$ $3.24 \mu \mathrm{M}$ (mean $\pm \mathrm{SD}$ ) nitrite, respectively. The number of viable ciliates incubated for $24 \mathrm{~h}$ with $0.2 \mathrm{mM}$ SIN-1 was reduced significantly to $25.0 \%$, and all ciliates were killed by incubation in concentrations above 0.5 mM SIN-1 (Fig. 1).

\section{Inhibitory effect of SOD, CAT and haemoglobin on SIN-1 toxicity}

Although SOD decreased the toxicity of SIN-1 on Uronema marinum, protection was not complete and was not improved by increasing the SOD concentration from 50 to $400 \mathrm{U} \mathrm{ml}^{-1}$ (Fig. 2). Addition of CAT ranging from 500 to $10000 \mathrm{U} \mathrm{ml}^{-1}$ completely protected $U$. marinum from SIN-1 toxicity. Ciliates exposed to CAT alone or CAT plus SIN-1 showed significantly higher and dose-dependent proliferation rates compared to the control. The combination of SOD and CAT was completely protective, but the proliferation rates of ciliates were lower than equal corresponding doses of CAT only (Fig. 3). Addition of haemoglobin, ranging from 0.5 to $2.0 \mathrm{mg} \mathrm{ml}^{-1}$, also protected $U$. marinum from SIN-1 toxicity, and increased proliferation rate dose-dependently (data not shown).

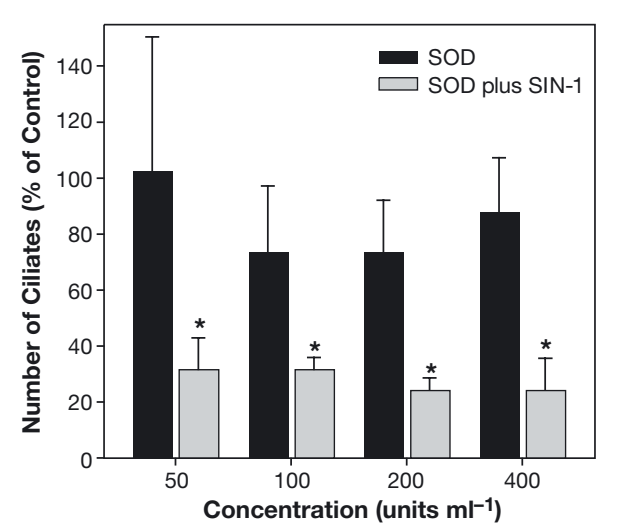

Fig. 2. Uronema marinum. Percentage of individuals exposed to various concentrations of superoxide dismutase (SOD) in minimum essential medium (MEM) for $24 \mathrm{~h}$ in the presence and absence of $1 \mathrm{mM}$ 3-morpholinosydnonimine (SIN-1). Ciliates exposed to $1 \mathrm{mM}$ SIN-1 alone died completely. Ciliates were counted by a haemocytometer, and data are expressed as means \pm SD of triplicate assays. ${ }^{*} \mathrm{p}<0.01$, versus ciliates cultured in MEM alone (control) 


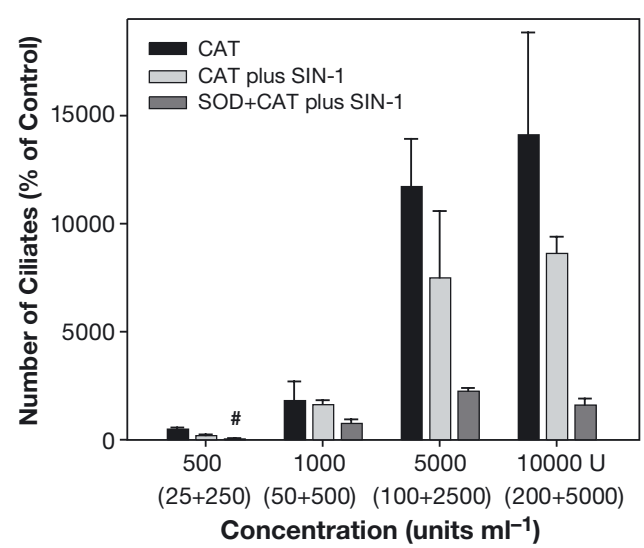

Fig. 3. Uronema marinum. Percentage of individuals exposed to various concentrations of catalase (CAT) and superoxide dismutase (SOD)+CAT (the concentrations used are shown in parentheses) in minimum essential medium (MEM) for $24 \mathrm{~h}$ in the presence and absence of $1 \mathrm{mM} 3$-morpholinosydnonimine (SIN-1). Ciliates exposed to $1 \mathrm{mM}$ SIN-1 alone died completely. Ciliates were counted by a haemocytometer, and data are expressed as means \pm SD of triplicate assays. All data were significant $(p<0.01)$ compared to ciliates cultured in

MEM alone (control), except a group designated as \#

\section{DISCUSSION}

The results of the present study suggest that peroxynitrite is more potently toxic to Uronema marinum than NO. Although $0.5 \mathrm{mM}$ SNAP showed toxicity to the ciliates, the level of NO generated was still higher than physiological ranges. NO produced by activated phagocytes expressing iNOS has been shown to function as a cytotoxic or cytostatic molecule and to inhibit the growth of pathogenic protozoa in mammals (Lin \& Chadee 1992, Oswald et al. 1994, Romao et al. 1999, Jarillo-Luna et al. 2002) and fish (Saeij et al. 2000, 2002, Scharsack et al. 2003a,b). It has been reported that exogenous NO released from the NO donors kill Trypanosoma cruzi (Vespa et al. 1994, Petray et al. 1995, Gobert et al. 1998) and Plasmodium falciparum (Rockett et al. 1991, Balmer et al. 2000) in a dose- and time-dependent fashion. As a whole, the NO-mediated inactivation of cysteine proteinases, which are critical for virulence or replication of many parasites, may represent an intriguing mechanism of antiparasitic host defence (Clark \& Rockett 1996, Colasanti et al. 2002). NO released by NO donors has been reported to inhibit cruzipain, the major cysteine proteinase from $T$. cruzi epimastigotes (Venturini et al. 2000), falcipain, the cruzipain-homologous cysteine proteinase from Plasmodium falciparum trophozoites (Venturini et al. 1998), and cysteine proteinase from Leishmania infantum (Salvati et al. 2001), via $S$-nitrosylation. However, in our previous study (Lee et al. 2003), the main excretory proteinase of $U$. marinum was not cysteine pro- teinase but metalloproteinase (Lee et al. 2003). Moreover, it has been reported that NO can up-regulate metalloproteinase activity (Murrell et al. 1995). It has been proposed that peroxynitrite is responsible for a significant portion of macrophage-derived cytotoxicity through a direct reaction of peroxynitrite with critical cellular components (Koppenol et al. 1992). Peroxynitrite produces potent cytotoxic actions against various microbes through disintegration and chemical modification of various biomolecules, such as membrane lipids (Radi et al. 1991, Rubbo et al. 1994), nucleic acids (Salgo et al. 1995), and proteins, including the nitration of tyrosine residues in proteins (Beckman 1996, Gow et al. 1996), which block tyrosine phosphorylation, a key event in signal transduction cascades.

In the present study, as little as $50 \mathrm{U} \mathrm{ml}^{-1}$ of SOD partially protected Uronema marinum against SIN-1 toxicity, but no greater protection was afforded by an increase in SOD. In the presence of SIN-1, SOD decreases peroxynitrite formation by scavenging superoxide, but results in hydrogen peroxide production. However, considering the higher reaction velocity of peroxynitrite than SOD to superoxide (Huie \& Padmaja 1993), the toxic effects of hydrogen peroxide in this experiment would be small. We also observed that SOD plus CAT protected $U$. marinum completely against SIN-1 toxicity. This may be partially due to scavenging of the hydrogen peroxide formed by SOD. However CAT alone completely protected against SIN-1 toxicity, and this effect was proportional to CAT concentration. The protection exerted by CAT against SIN-1 toxicity might be due to scavenging of NO by CAT, which thereby reduced peroxynitrite formation. CAT has a ferriheme active site that readily binds NO (Murphy \& Sies 1991). Haemoglobin, commonly used as a NO scavenger, was also protective against SIN-1 toxicity in the present study. A significantly higher number of $U$. marinum incubated in the presence of CAT or haemoglobin suggests that iron-containing proteins induce fast proliferation of the ciliates.

Our previous in vitro studies demonstrated that the respiratory burst activity of olive flounder phagocytes was inhibited by live Uronema marinum (Kwon et al. 2002 , 2003), which suggests that superoxide anions, required for peroxynitrite formation, are reduced. Moreover, the ciliates secreted SOD and CAT into their culture medium (Kwon et al. 2002, 2003). Resistance of $U$. marinum to oxidative and nitrative stress may allow this pathogen to withstand NO- and oxygen-radicaldependent killing mechanisms of phagocytic cells.

Acknowledgements. This work was supported by Grant No. R01-2000-000-00215 from the Basic Research Program of the Korea Science \& Engineering Foundation. 


\section{LITERATURE CITED}

Balmer P, Phillips HM, Maestre AE, McMonagle FA, Phillips RS (2000) The effect of nitric oxide on the growth of Plasmodium falciparum, $P$. chabaudi and $P$. berghei in vitro. Parasite Immunol 22:97-106

Beckman JS (1996) Oxidative damage and tyrosine nitration from peroxynitrite. Chem Res Toxicol 9:836-844

Bogdan C, Rollinghoff M, Diefenbach A (2000) Reactive oxygen and reactive nitrogen intermediates in innate and specific immunity. Curr Opin Immunol 12:64-76

Campos-Perez JJ, Ward M, Grabowski PS, Ellis AE, Secombes CJ (2000) The gills are an important site of iNOS expression in rainbow trout Oncorhynchus mykiss after challenge with the Gram-positive pathogen Renibacterium salmoninarum. Immunology 99:153-161

Carreras MC, Pargament GA, Catz SD, Poderoso JJ, Boveris A (1994) Kinetics of nitric oxide and hydrogen peroxide production and formation of peroxynitrite during the respiratory burst of human neutrophils. FEBS Lett 341:65-68

Cheung PJ, Nigrelli RF, Ruggieri GD (1980) Studies on the morphology of Uronema marinum Dujardin (Ciliatea: Uronematidae) with a description of the histopatology of the infection in marine fishes. J Fish Dis 3:295-303

Clark IA, Rockett KA (1996) Nitric oxide and parasitic disease. Adv Parasitol 37:1-56

Colasanti M, Gradoni L, Mattu M, Persichini T, Salvati L, Venturini G, Ascenzi P (2002) Molecular bases for the antiparasitic effect of NO (Review). Int J Mol Med 9:131-134

Denicola A, Rubbo H, Rodriguez D, Radi R (1993) Peroxynitrite-mediated cytotoxicity to Trypanosoma cruzi. Arch Biochem Biophys 304:279-286

Dragesco A, Dragesco J, Coste F, Gasc C, Romestand B, Raymond J, Bouix G (1995) Philasterides dicentrarchi, n. sp. (Ciliophora, Scuticociliatida), a histophagous opportunistic parasite of Dicentrachus labrax (Linnaeus. 1758), a reared marine fish. Eur J Protistol 31:327-340

Dyková I, Figueras A (1994) Histopathological changes in turbot Scophthalmus maximus due to a histophagous ciliate. Dis Aquat Org 18:5-9

Eckmann L, Laurent F, Langford TD, Hetsko ML, Smith JR, Kagnoff MF, Gillin FD (2000) Nitric oxide production by human intestinal epithelial cells and competition for arginine as potential determinants of host defense against the lumen-dwelling pathogen Giardia lamblia. J Immunol 164:1478-1487

Feelisch M (1991) The biochemical pathways of nitric oxide formation from nitrovasodilators: appropriate choice of exogenous NO donor and aspects of preparation and handling of aqueous NO solution. J Cardiovasc Pharmacol 17 (Suppl 3):25-33

Gill PA, Calinan RB (1997) Ulcerative dermatitis associated with Uronema sp. infection of farmed sand whiting Sillago ciliata. Aust Vet J 75:357

Gobert AP, Semballa S, Daulouede S, Lesthelle S, Taxile M, Veyret B, Vincendeau P (1998) Murine macrophages use oxygen- and nitric oxide-dependent mechanisms to synthesize S-nitroso-albumin and to kill extracellular trypanosomes. Infect Immunol 66:4068-4072

Gow AJ, Duran D, Malcolm S, Ischiropoulos H (1996) Effects of peroxynitrite-induced protein modifications on tyrosine phosphorylation and degradation. FEBS Lett 385:63-66

Hogg N, Darley-Usmar VM, Wilson MT, Moncada S (1992) Production of hydroxyl radicals from the simultaneous generation of superoxide and nitric oxide. Biochem J 281: 419-424

Holm P, Kankaanranta H, Metsä-Ketelä T, Moilanen E (1998)
Radical releasing properties of nitric oxide donors GEA 3162, SIN-1 and $S$-nitroso- $N$-acetylpenicillamine. Eur J Pharmacol 346:97-102

Huie RE, Padmaja S (1993) The reaction of NO with superoxide. Free Radical Res Commun 18:195-199

Iglesias R, Paramá A, Alvarez MF, Leiro J, Fernández J, Sanmartín ML (2001) Philasterides dicentrarchi (Ciliophora, Scuticociliatida) as the causative agent of scuticociliatosis in farmed turbot Scophthalmus maximus in Galicia (NW Spain). Dis Aquat Org 46:47-55

Ischiropoulos H, Zhu L, Beckman JS (1992) Peroxynitrite formation from macrophage-derived nitric oxide. Arch Biochem Biophys 298:446-451

Jarillo-Luna RA, Campos-Rodriguez R, Tsutsumi V (2002) Entamoeba histolytica: immunohistochemical study of hepatic amoebiasis in mouse. Neutrophils and nitric oxide as possible factors of resistance. Exp Parasitol 101:40-56

Jee BY, Kim YC, Park MS (2001) Morphology and biology of parasite responsible for scuticociliatosis of cultured olive flounder Paralichthys olivaceus. Dis Aquat Org 47:49-55

Koppenol WH, Moreno JJ, Pryor WA, Ischiropoulos H, Beckman JS (1992) Peroxynitrite, a cloaked oxidant formed by nitric oxide and superoxide. Chem Res Toxicol 5:834-842

Kwon SR, Kim CS, Chung JK, Lee HH, Kim KH (2002) Inhibition chemiluminescent response of olive flounder Paralichthys olivaceus phagocytes by the scuticociliate parasite Uronema marinum. Dis Aquat Org 52:119-122

Kwon SR, Kim CS, Kim KH (2003) Differences between shortand long-term cultures of Uronema marinum (Ciliophora: Scuticociliatida) in chemiluminescence inhibitory activity, antioxidative enzyme and protease activity. Aquaculture 221:107-114

Lee EH, Kim CS, Cho JB, Ahn KJ, Kim KH (2003) Measurement of protease activity of live Uronema marinum (Ciliata: Scuticociliatida) by fluorescence polarization. Dis Aquat Org 54:85-88

Liew FY, Li Y, Millott S (1990) Tumor necrosis factor-alpha synergizes with IFN-gamma in mediating killing of Leishmania major through the induction of nitric oxide. J Immunol 145:4306-4310

Lin JY, Chadee K (1992) Macrophage cytotoxicity against Entamoeba histolytica trophozoites is mediated by oxide nitric from L-arginine. J Immunol 148:3999-4005

Munday BL, O'Donoghue PJ, Watts M, Rough K, Hawkesford $T$ (1997) Fatal encephalitis due to the scuticociliate Uronema nigricans in sea-caged, southern bluefin tuna Thunnus maccoyii. Dis Aquat Org 30:17-25

Murphy ME, Sies H (1991) Reversible conversion of nitroxyl anion to nitric oxide by superoxide dismutase. Proc Natl Acad Sci USA 88:10860-10864

Murrell GAC, Jang D, Williams RJ (1995) Nitric oxide activates metalloprotease enzymes in articular cartilage. Biochem Biophys Res Commun 206:15-21

Nathan C (1992) Nitric oxide as a secretory product of mammalian cells. Fed Am Soc Exp Biol J 6:3051-3064

Nathan C, Shiloh MU (2000) Reactive oxygen and nitrogen intermediates in the relationship between mammalian hosts and microbial pathogens. Proc Natl Acad Sci USA 97:8841-8848

Neumann NF, Fagan D, Belosevic M (1995) Macrophage activating factor(s) secreted by mitogen stimulated goldfish kidney leukocytes synergize with bacterial lipopolysaccharide to induce nitric oxide production in teleost macrophages. Dev Comp Immunol 19:473-482

Oswald IP, Wynn TA, Sher A, James SL (1994) NO as an effector molecule of parasite killing: modulation of its synthesis by cytokines. Comp Biochem Physiol C 108:11-18 
Petray P, Castanos-Velez E, Grinstein S, Orn A, Rottenberg ME (1995) Role of nitric oxide in resistance and histopathology during experimental infection with Trypanosoma cruzi. Immunol Lett 47:121-126

Radi R, Beckman JS, Bush KM, Freeman BA (1991) Peroxynitrite induced membrane lipid peroxidation: the cytotoxic potential of superoxide and nitric oxide. Arch Biochem Biophys 288:481-487

Rockett KA, Awburn MM, Cowden WB, Clark IA (1991) Killing of Plasmodium falciparum in vitro by nitric oxide derivatives. Infect Immunol 59:3280-3283

Romao PR, Fonseca SG, Hothersall JS, Noronha-Dutra AA, Ferreira SH, Cunha FQ (1999) Glutathione protects macrophages and Leishmania major against nitric oxidemediated cytotoxicity. Parasitology 118:559-566

Rubbo H, Radi R, Trujillo M, Telleri R, Kalyanaraman B, Barnes S, Kirk M, Freeman BA (1994) Nitric oxide regulation of superoxide and peroxynitrite-dependent lipid peroxidation. Formation of novel nitrogen-containing oxidized lipid derivatives. J Biol Chem 269:26066-26075

Saeij JPJ, Stet RJM, Groeneveld A, Verburg-van Kemenade LBM, van Muiswinkel WB, Wiegertjes GF (2000) Molecular and functional characterization of a fish iNOS. Immunogenetic 51:339-346

Saeij JP, Van Muiswinkel WB, Groeneveld A, Wiegertjes GF (2002) Immune modulation by fish kinetoplastid parasites: a role for nitric oxide. Parasitology 124:77-86

Salgo MG, Bermudez E, Squadrito GL, Pryor WA (1995) Peroxynitrite causes DNA damage and oxidation of thiols in rat thymocytes. Arch Biochem Biophys 322:500-505

Salvati L, Mattu M, Colasanti M, Scalone A, Venturini G, Gradoni L, Ascenzi P (2001) NO donors inhibit Leishmania infantum cysteine proteinase activity. Biochim Biophys Acta 1545:357-366

Scharsack JP, Steinhagen D, Kleczka C, Schmidt JO, Körting W, Michael RD, Leibold W, Schuberth HJ (2003a) The

Editorial responsibility: Wolfgang Körting,

Hannover, Germany haemoflagellate Trypanoplasma borreli induces the production of nitric oxide, which is associated with modulation of carp (Cyprinus carpio L.) leucocyte functions. Fish Shellfish Immunol 14:207-222

Scharsack JP, Steinhagen D, Kleczka C, Schmidt JO, Körting W, Michael RD, Leibold W, Schuberth HJ (2003b) Head kidney neutrophils of carp (Cyprinus carpio L.) are functionally modulated by the haemoflagellate Trypanoplasma borreli. Fish Shellfish Immunol 14:389-403

Schoor WP, Plumb JA (1994) Indiation of nitric oxide synthase in channel catfish Ictalurus punctatus by Edwardsiella ictaruli. Dis Aquat Org 19:153-155

Sterud E, Hansen MK, Mo TA (2000) Systemic infecion with Uronema-like ciliates in farmed turbot, Scophthalmus maximus (L.). J Fish Dis 23:33-37

Thomas GR, McCrossan M, Selkirk ME (1997) Cytostatic and cytotoxic effects of activated macrophages and nitric oxide donors on Brugia malayi. Infect Immunol 65:2732-2739

Thompson CL Jr, Moewus L (1964) Miamiensis avidus n.g. n.s., a marine facultative parasite in the ciliate order Hymenostomatida. J Protozool 11:378-381

Venturini G, Fioravanti E, Colasanti M, Persichini T, Ascenzi $\mathrm{P}$ (1998) Cys25-nitrosylation inactivates papain. Biochem Mol Biol Int 46:425-428

Venturini G, Salvati L, Muolo M, Colasanti M, Gradoni L, Ascenzi P (2000) Nitric oxide inhibits cruzipain, the major papain-like cysteine proteinase from Trypanosoma cruzi. Biochem Biophys Res Commun 270:437-441

Vespa GNR, Cunha FQ, Silva JS (1994) Nitric oxide is involved in control of Trypanosoma cruzi-induced parasitaemia and directly kills the parasite in vitro. Infect Immunol 62:5177-5182

Yoshinaga T, Nakazoe J (1993) Isolation and in vitro cultivation of an unidentified ciliate causing scuticociliatosis in Japanese flounder (Paralichthys olivaceus). Gyobyo Kenkyu 28:131-134

Submitted: July 25, 2003; Accepted: September 25, 2003 Proofs received from author(s): January 26, 2004 